\title{
Laboratory Analysis of a Piston-Actuated Pressure-Reducing Valve under Low Flow Conditions
}

\author{
Valentina Marsili * , Riccardo Zarbo, Stefano Alvisi ${ }^{\circ}$ and Marco Franchini $(\mathbb{D}$ \\ Department of Engineering, University of Ferrara, Via Saragat 1, 44122 Ferrara, Italy; \\ riccardo.zarbo@student.unife.it (R.Z.); stefano.alvisi@unife.it (S.A.); marco.franchini@unife.it (M.F.) \\ * Correspondence: valentina.marsili@unife.it; Tel.: +39-0532-974932
}

Received: 31 January 2020; Accepted: 19 March 2020; Published: 26 March 2020

check for updates

\begin{abstract}
The effectiveness of pressure-reducing valves (PRVs) for optimal pressure management of water distribution networks (WDNs) is proven, but problems and operational limitations have been highlighted by some recent experiences. In this study, we analyse the functioning of a piston-actuated pressure-reducing valve (PA-PRV) with a mechanical pilot which is subjected to low-flow regimes, a condition that is often observed in real water distribution networks. The analyses were carried out by means of laboratory tests featuring two sets of experiments, i.e., (a) by testing the behaviour of the PRV when a pre-established initial value and subsequent variation of flow rate occurs in the system and (b) by testing the PRV against a temporal series of flow rates observed at the inlet section of a real district metered area. The first set of tests showed that the PA-PRV tends not to maintain pressure at the imposed set-point and exhibits an unstable behaviour characterised by significant pressure oscillations under some flow rate conditions. The second set of laboratory tests showed that the anomalous behaviour identified in the first set of tests can occur under ordinary operational conditions of a network.
\end{abstract}

Keywords: pressure-reducing valve (PRV); laboratory analyses; anomalies; instability

\section{Introduction}

The processes of managing and monitoring complex water distribution networks are often based on the design of district metered areas (DMAs) [1-7], which allow for easier system monitoring and leakage identification [8]. In the partitioning of networks into DMAs, pressure-reducing valves (PRVs), or devices capable of regulating the pressure downstream of the installation site, are often used [9-12]. Indeed, controlling pressures in the district allows limiting the water losses in the system itself [13-17].

Among the different types of pressure-reducing valves, the most common are diaphragm valves, in which the pressure-regulating device operates in a direction transverse to the flow. Another type of pressure regulating valves, even though less frequently used, is piston-actuated valves, in which the regulating device operates in a direction parallel to the flow. The pilot that regulates the downstream pressure control mechanism can be mechanical or remotely electronically controlled, even in a real-time mode.

In the literature, diaphragm pressure-reducing valves have been extensively investigated, from device modelling, possibly in combination with an electronic control apparatus [18-24] also under transient regimes [25], to the optimisation of their location in networks and their setting value [26-37]. The efficiency of the use of PRVs in reducing losses has been demonstrated in several studies $[13,14,16,17,38]$.

However, the physical behaviour of PRVs has been investigated by only a limited number of studies. In particular, very few studies (e.g., [23]) focused the attention on static and dynamic models of a PRV, as done more extensively for other types of valves like pressure relief valves $[39,40]$, whereas 
some other studies focused on laboratory tests and analysis of the PRV behaviour. Within this latter case, Meniconi et al. [41] characterised the behaviour of a diaphragm PRV through laboratory tests, both under steady and unsteady flow conditions, demonstrating the versatility of the device as an effective tool for pressure management. The same authors observed that pressure oscillations due to PRV adjustment manoeuvres are of short duration and do not result in any particular upstream propagations [42]. Furthermore, the same authors [43] observed that the PRV tends to act as a discontinuity in the presence of a pressure transient, splitting the system into two parts, and preventing any disturbances or pressure oscillations generated downstream of the valve from propagating upstream of the valve itself.

Other studies have instead highlighted some problems relating to the singular behaviours of these devices, an issue that also concerns different types of control valves [44]. More specifically, some recent studies have shown the occurrence of instability in electronically controlled diaphragm PRVs under low-flow regimes. In particular, starting from field measurements, Ulanicki and Skworcow [45] observed an unstable behaviour of PRVs below certain flow rates. Drawing on the latter study and through numerical simulations, Janus and Ulanicki [19] showed that in the presence of a small randomly variable flow rate, the electronically controlled diaphragm PRV cannot maintain the pressure set-point, resulting in pressure oscillations around the set-point itself. In the context of fault detection and diagnosis with respect to diaphragm PRVs in water distribution networks, Changklom and Stoianov [46] similarly identify possible anomalous behaviours of these devices that can lead to malfunctions and failures. It is worth stressing that the aforementioned studies mainly refer to diaphragm PRVs and, to authors' knowledge, no study on the hydraulic application of a piston-actuated PRV is currently available.

Moving from these considerations, this paper is aimed at characterising the behaviour of a piston-actuated PRV (hereinafter labelled as PA-PRV) with a mechanical pilot. In particular, like other studies on diaphragm PRVs which are focused on valve field behaviour rather than on its static and dynamic modelling, the analysis are developed through laboratory tests by installing the PA-PRV in a hydraulic testbed and subjecting it to low-flow regimes, a condition consistent with the normal operating conditions of real small networks or DMAs. In fact, the analyses are carried out by means of laboratory tests, in which the PA-PRV is subjected to both pre-established flow rates and historical flow rates observed at the inlet section of a small DMA. The main characteristics of the pressure reduction valve and the testbed are given below and the tests carried out are then described. The results obtained are analysed and compared with those reported in other studies and, finally, some concluding remarks are given.

\section{Materials and Methods}

\subsection{The PA-PRV and the Testbed}

The PA-PRV analysed in this study (Figure 1a,b) consists of a plastic valve and an independent control unit made up of a pilot and a three-position selector of the C-valve type marketed by Saisanket Ltd [47].

The three-way pilot controls the valve and in particular the movement of the piston, which in turn controls the pressure downstream of the valve. The piston is part of the double-chambered and bidirectional actuator system. The main closed control chamber and the secondary closing control chamber remain isolated from the valve's flow (see Figure 2). 
(a)

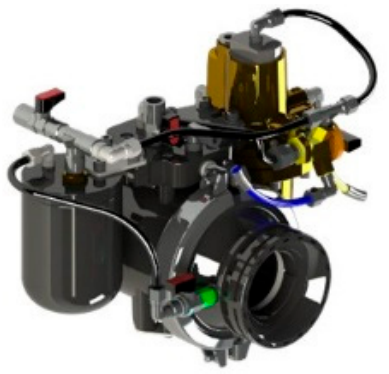

(b)

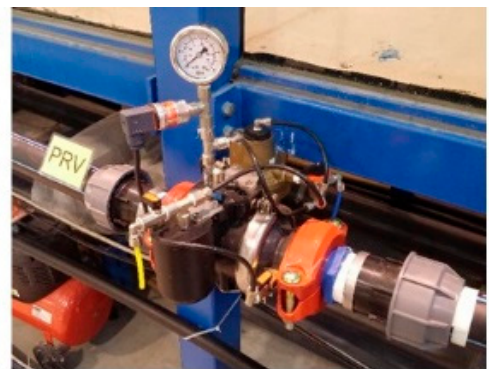

Figure 1. (a) The piston-actuated pressure-reducing valve (PA-PRV) with mechanical pilot; (b) the device installed in the hydraulic system.
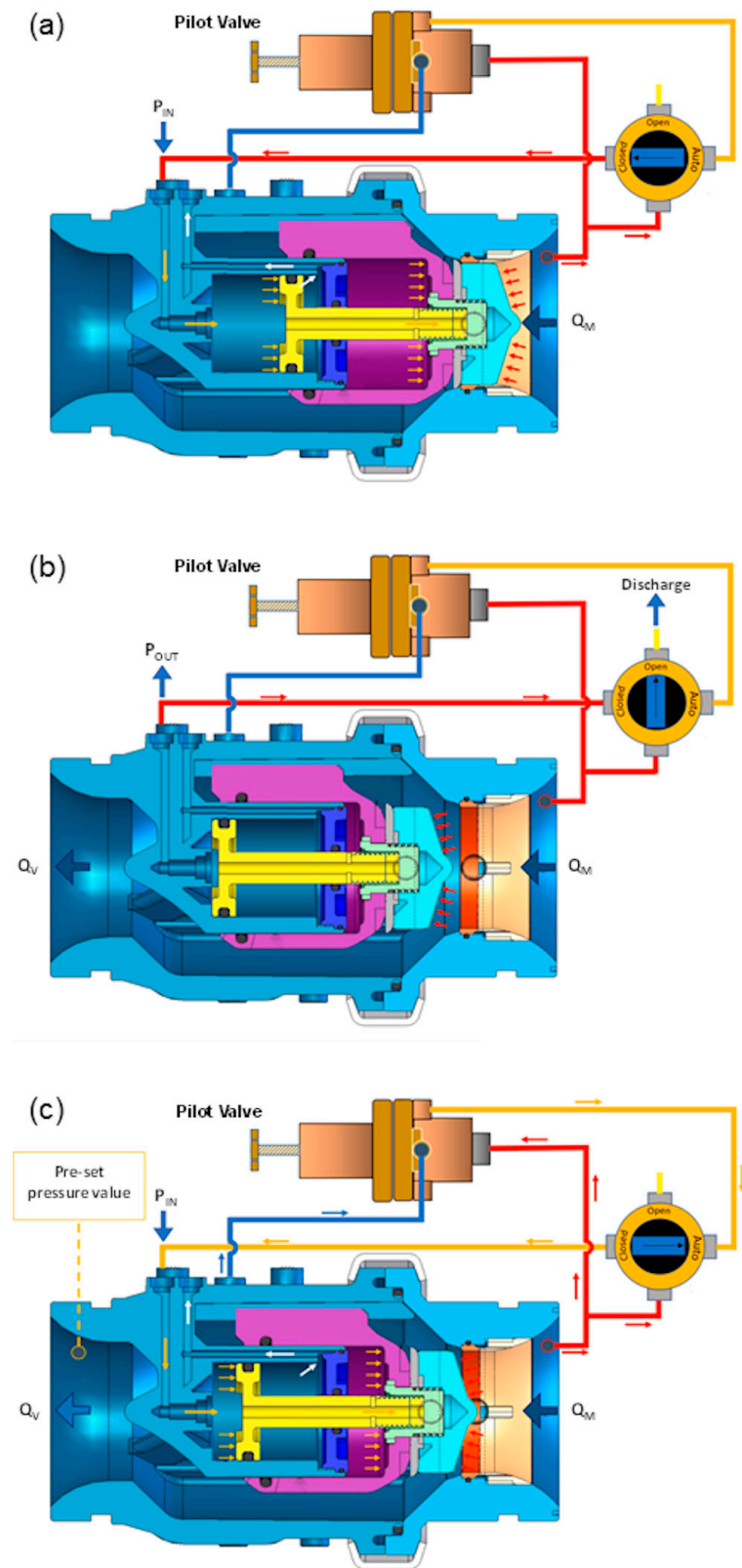

Figure 2. Scheme of the PA-PRV showing the inner structure of the device and the adjustment mechanism in case of (a) complete closure, (b) complete opening and (c) modulating functioning. 
In greater detail, the operating principle of the device is based on a balance of forces that is generated between the head of the piston and the pressure in the control chambers behind the piston itself. The force required to move the piston is derived from the high pressure upstream of the valve modulated by the pilot and then applied inside the closed control chamber. The ratio between the inner hydraulic surface area of the chamber and the external surface area allows the piston to move back and forth, providing a drive which enables the actuator to adjust to the required position, thus maintaining the pre-set parameter of downstream pressure (hereinafter, set-point). Control is applied by venting or supplying fluid to the closed control chamber (modulating functioning, see Figure 2c). In the closure position (Figure 2a), upstream pressure applied to the closing control chamber, on both front and back piston, creates a superior closing force overcoming upstream pressure applied to the actuator, thus closing the valve. In order to reach the opening position (Figure 2b), the closing control chamber is vented while upstream pressure applied to the actuator creates a force that opens the valve.

The functioning of the device is based on the proprietary technology "Linear Flow Linear Control (LFLC)" which replaces a manual system that regulates the piston speed adjustment. This technology is based on the double-chambered actuator system which produces a soft closure, theoretically capable of preventing the occurrence of potentially dangerous pressure transients in the system. From an operational standpoint, the closed control chamber is directly connected to the pilot valve while the closing control chamber is completely filled with air in direct contact with the atmosphere through a specific hole on the valve body. The adjustment speed of the piston depends on the speed at which the air enters or leaves the secondary control chamber. The valve has a "Normally Open" function, which ensures that the valve will remain open in the event of pilot anomalies and, according to the manufacturer, the time required for the full stroke closure or opening of the PA-PRV results between 0.8 and $3.7 \mathrm{~s}$ [47].

The PA-PRV considered has a nominal diameter DN of $50 \mathrm{~mm}$. The operational range of the valve indicated by the manufacturer is between 0 and 25 bar and between 0 and $80 \mathrm{~m}^{3} / \mathrm{h}$ and the tolerance with respect to the set value of the downstream pressure is \pm 0.05 bar.

The behaviour of the PA-PRV was investigated through a set of laboratory tests performed using the hydraulic system located in the Hydraulic Laboratory of the Engineering Department of the University of Ferrara, the layout of which is illustrated in Figure 3.

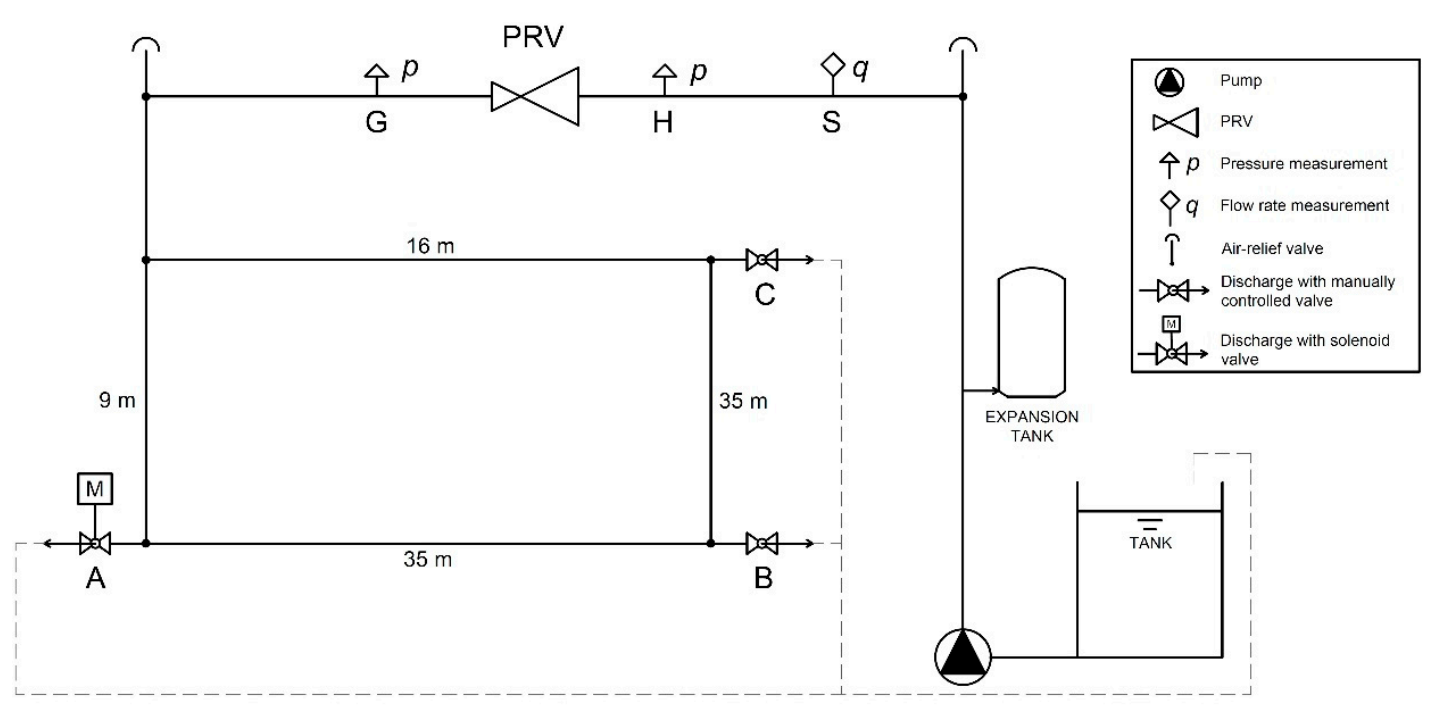

Figure 3. Layout of the testbed installed in the Hydraulics Laboratory of the University of Ferrara.

The closed hydraulic system is fed from a tank with a capacity of $0.9 \mathrm{~m}^{3}$ by a centrifugal pump which provides, at the best efficiency point, a flow rate of approximately $1 \mathrm{~L} / \mathrm{s}$ and a head of $52 \mathrm{~m}$. An 
electronic pressure switch and an expansion vessel are installed to protect the pumping system against dry-running and pressure fluctuations in the network, respectively.

The supply pipe consists of a polyethylene pipe with a diameter of $63 \mathrm{~mm}$ (PN 16) and a length of approximately $10 \mathrm{~m}$, along which the PA-PRV, two pressure measurement sections, upstream and downstream of the PA-PRV (respectively, sections H and G in Figure 3), and an electromagnetic flowmeter (section $\mathrm{S}$ in Figure 3) are installed. The supply pipe is connected to a polyethylene loop with a diameter of $40 \mathrm{~mm}$ (PN 10) for a total length of $100 \mathrm{~m}$ and characterised by the presence of three junctions where the discharge can be released towards the tank through a solenoid valve, indicated with the letter A in Figure 3 and two ball valves indicated with the letters B and C in Figure 3.

The degree of opening of the three valves located at sections $A, B$ and $C$ allows the discharge flowing out from the loop towards the tank to be modulated and, consequently, makes it possible to control the discharge in the supply pipe flowing through the PA-PRV. In particular, the solenoid valve installed at manoeuvring section $\mathrm{A}$ is characterised by a remotely controlled modular opening, while the ball valves at sections $B$ and $C$ are manually controlled. The polyethylene loop and the three sections (A, B and C) basically represent a simple loop of a water distribution network with the associated water utility connections. From an operational standpoint, the flow from each of the three sections A, B and C is discharged into the supply tank, thus closing the hydraulic circuit.

During the experimental tests, the flow rate and the pressure at strategic sections of the system were monitored; in particular, the following instruments were installed: 1 electromagnetic flowmeter (DN 50) which outputs an electric current signal (4 to $20 \mathrm{~mA}$ ) at section S, and 3 membrane pressure transducers which output a voltage signal $(0$ to $10 \mathrm{~V})$, upstream and downstream of the PRV, at sections $\mathrm{H}$ and $\mathrm{G}$, respectively, and at manoeuvring section $\mathrm{A}$.

The simultaneous sampling of the pressure and flow rate was performed at a frequency of $100 \mathrm{~Hz}$ through a series of modules designed to convert the analogue signals into digital data; the acquisition was managed with the programming software LabView ${ }^{\circledR}$.

\subsection{Laboratory Tests}

The characterisation of the PA-PRV was conducted through a set of laboratory tests aimed at verifying the ability of the PA-PRV to maintain an imposed set-point at the downstream section with respect to different flow rates. The laboratory tests can be schematically divided into two phases. In a first phase, the system was subjected to a rapid flow rate variation $\Delta \mathrm{Q}$ starting from a pre-established

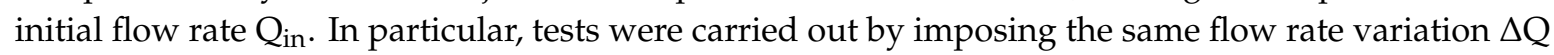
and considering different values of the initial flow rate $Q_{i n}$. During the second phase, the behaviour of the PA-PRV was analysed by subjecting the system to a series of flow rates historically observed at the inlet section of a small DMA. In both cases the set-point imposed was equal to 2.4 bar.

During the first phase, the behaviour of the PA-PRV was analysed in relation to a flow rate variation $\Delta \mathrm{Q}$ within the system equal to $0.5 \mathrm{~L} / \mathrm{s}$ starting from different values of the initial flow rate $\mathrm{Q}_{\text {in }}$. In particular, nine initial flow rates $Q_{\text {in }}$ with values between 1.4 and $0.6 \mathrm{~L} / \mathrm{s}$, with a step of $0.1 \mathrm{~L} / \mathrm{s}$, and corresponding final flow rates $Q_{\text {fin }}$ between 0.9 and $0.1 \mathrm{~L} / \mathrm{s}$, were considered. The initial flow rate $Q_{\text {in }}$ characterising each test was obtained by fixing a certain modulation of the valves at sections $\mathrm{A}$ and $\mathrm{B}$ through a trial and error procedure (see Table 1 ) while the valve at section $C$ was systematically closed. On the other hand, the final flow rate $Q_{\text {fin }}$ at the end of each test was obtained through a complete closure of the ball valve located at section $B$.

Summarizing, the degree of opening of the valves A and B were determined by trial and error so that they would determine an initial flow rate in the system equal to $Q_{\text {in }}$ and a final flow rate equal to $\mathrm{Q}_{\text {fin }}$ following the complete closure of the ball valve located at section $\mathrm{B}$. In order to evaluate the variability of the behaviour of the PA-PRV with respect to the same boundary conditions, each test was repeated five times and for each test the sampling of the pressure and flow rate was carried out for a duration of $6 \mathrm{~min}, 1 \mathrm{~min}$ before and $5 \mathrm{~min}$ after the flow rate reduction manoeuvre. 
Table 1. Boundary conditions characterising the nine test configurations.

\begin{tabular}{ccccccc}
\hline Test & Qin (L/s) & Qfin (L/s) & $\Delta \mathbf{Q}(\mathbf{L} / \mathbf{s})$ & $\mathbf{A ~ ( \% )}$ & $\mathbf{B ~ ( \% )}$ & $\mathbf{C}(\%)$ \\
\hline a & 1.4 & 0.9 & 0.5 & 100 & 70 & 0 \\
b & 1.3 & 0.8 & 0.5 & 55 & 70 & 0 \\
c & 1.2 & 0.7 & 0.5 & 47 & 60 & 0 \\
d & 1.1 & 0.6 & 0.5 & 45 & 60 & 0 \\
e & 1.0 & 0.5 & 0.5 & 39 & 55 & 0 \\
f & 0.9 & 0.4 & 0.5 & 34 & 50 & 0 \\
g & 0.8 & 0.3 & 0.5 & 29 & 49 & 0 \\
h & 0.7 & 0.2 & 0.5 & 24 & 49 & 0 \\
i & 0.6 & 0.1 & 0.5 & 18 & 50 & 0 \\
\hline
\end{tabular}

The second phase of testing was aimed at the validation of the results obtained and consisted of an analysis of the PA-PRV based on a real-time series of flow rates. In particular, a 1 min time step time series of flow rates observed at the inlet section of a district was imposed within the laboratory system in order to show that the first phase test conditions can be found in ordinary operational conditions of real DMAs. The data gathered for this purpose refer to the water distribution network of Gorino Ferrarese (Ferrara, Italy), which serves approximately 300 users [48]. The flow rates were measured at the inlet of the $160 \mathrm{~mm}$ diameter pipes that supply the district (where no PRV is actually installed), over a two day time window with a 1 min sampling step (from 00:00, 15/01/2018 to 07:00, 17/01/2018). Flow rates observed at the inlet section of the district metered area are in general very low, varying between 3.1 and $0.1 \mathrm{~L} / \mathrm{s}$ as shown in Figure 4 .

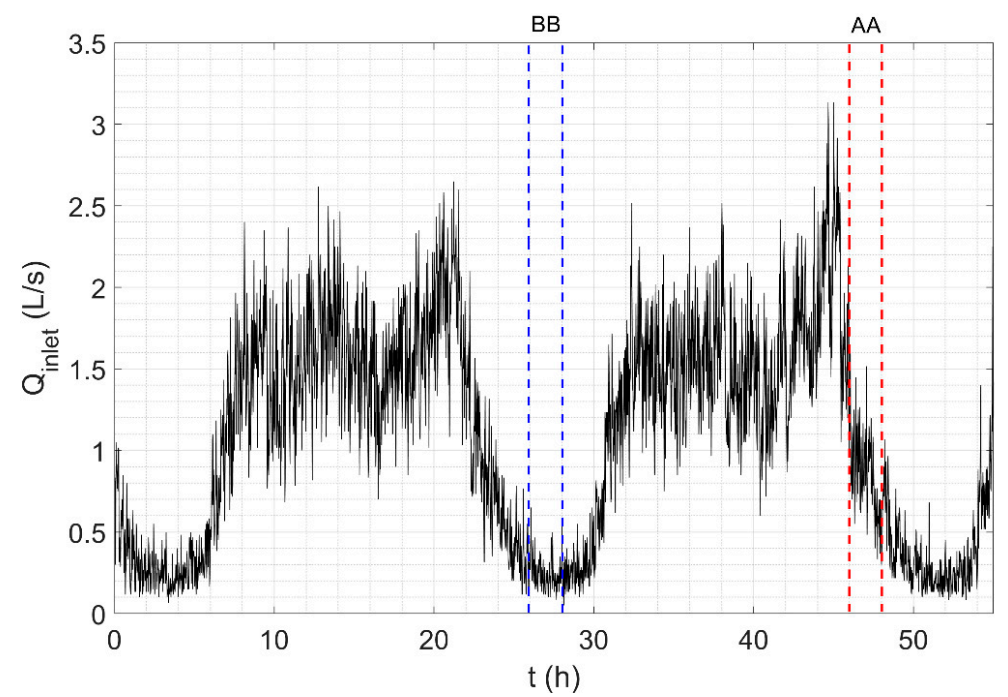

Figure 4. Flow rates observed at the inlet section of the district metered area of Gorino Ferrarese (Ferrara, Italy) from 15/01/2018 to early 17/01/2018. The periods AA and BB reproduced in the laboratory tests are also indicated.

Two distinct tests were conducted in order to characterise the behaviour of the PA-PRV with respect to different flow regimes, which were in any case in line with those of the tests in the first phase. Each test had a duration of two hours, corresponding, respectively, to the time window from 22:00 to 24:00, 16/01/2018 (period AA, see Figure 4), and to the time window from 02:00 to 04:00, 16/01/2018 (period BB, see Figure 4).

From an operational standpoint, the imposition of observed flow rates within the system was achieved for both test periods through the automation of the solenoid valve installed at section A, while the ball valves at $B$ and $C$ were kept fixed. In particular, a degree of opening of $25 \%$ was imposed for the ball valve at $B$ while the ball valve at $C$ was completely closed. 


\section{Results and Discussion}

Pressure signals observed downstream of the PA-PRV (section G) are shown in Figure 5 for the nine test configurations, each test being repeated five times. Based on the pressure signals obtained, it can be observed that the PA-PRV exhibits a correct behaviour for final flow rates $Q_{\text {fin }}$ higher than or equal to $0.7 \mathrm{~L} / \mathrm{s}$ (tests (a), (b) and (c) in Table 1). Indeed, with reference to Figure 5a-c, the pressure signal observed downstream of the PA-PRV shows some marked oscillations due to the flow rate reduction manoeuvre, but afterwards the pressure tends to stabilise around the imposed set-point.

(a)

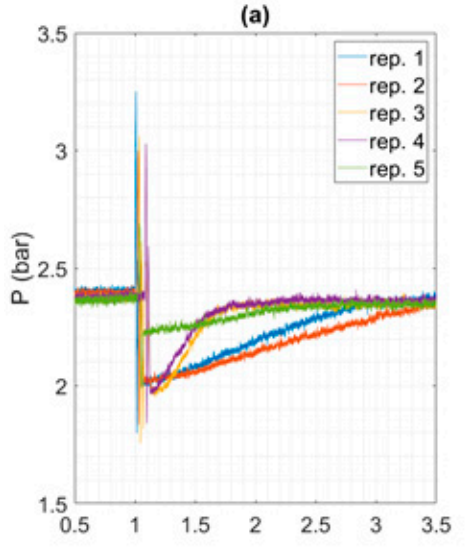

(d)

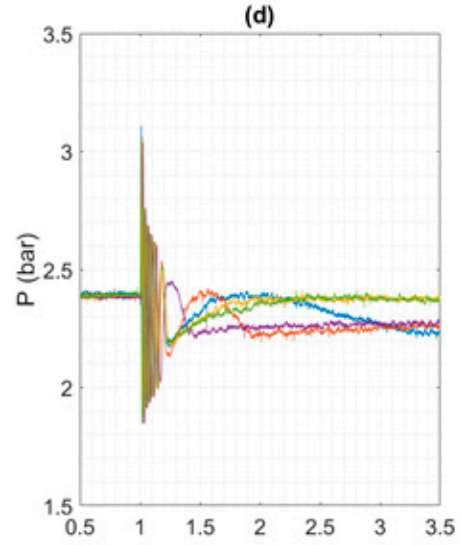

(g)

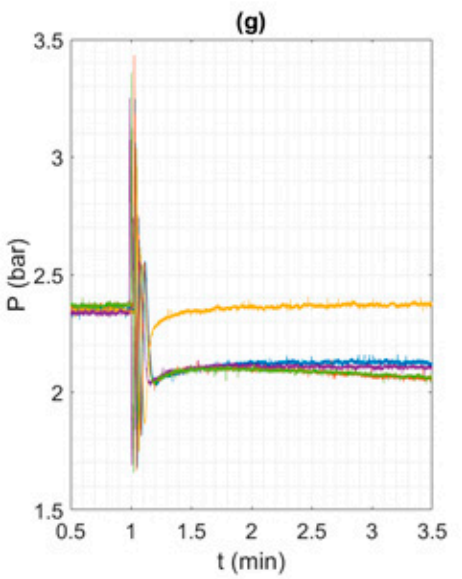

(b)

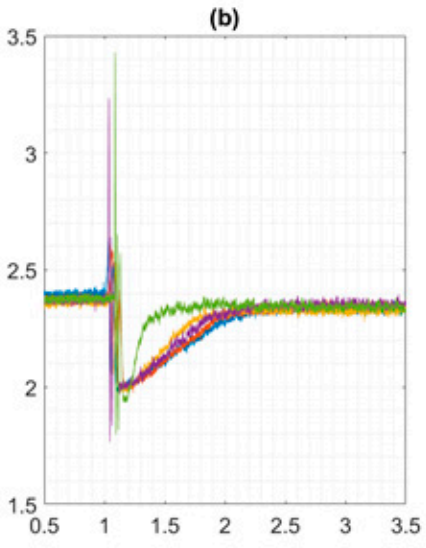

(e)

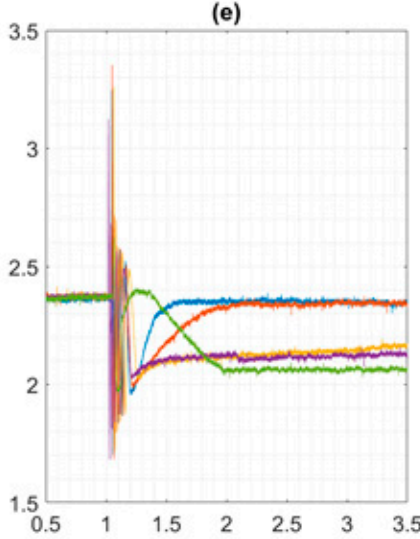

(h)

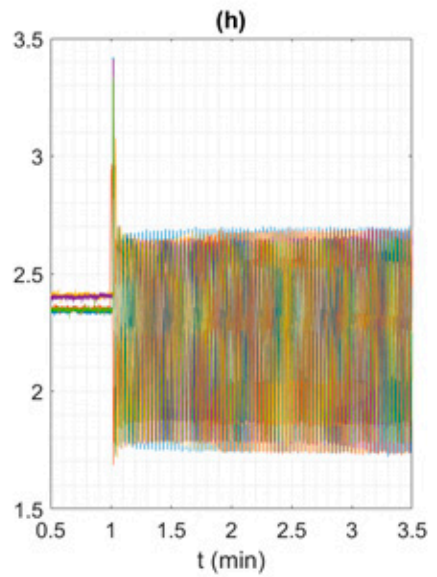

(c)

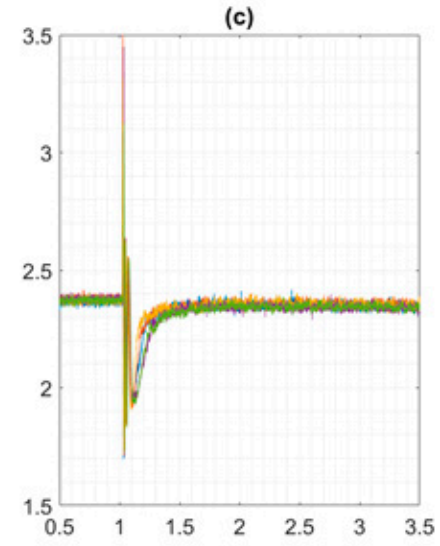

(f)

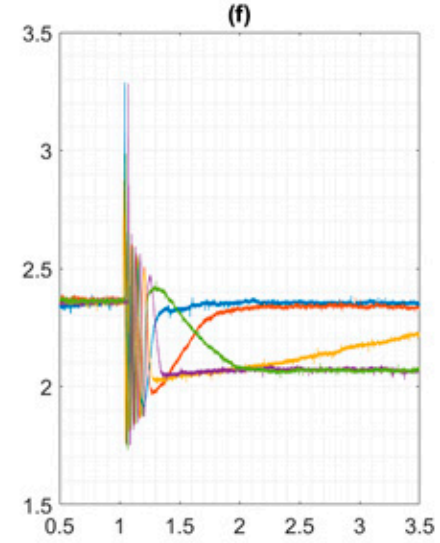

(i)

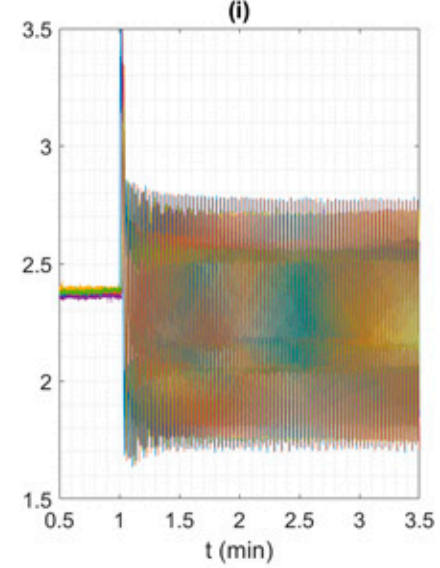

Figure 5. Pressure signals sampled downstream of the PA-PRV (section G) during the nine tests (a-i), each repeated five times. 
The time it takes for the downstream pressure to become stabilised, that is, the stabilisation time intervals (hereafter labelled as STs), varies with an apparently decreasing trend as the final flow rate $\mathrm{Q}_{\text {fin }}$ decreases, as summarised in Table 2.

Table 2. Stabilisation time intervals (or STs) for tests (a), (b) and (c).

\begin{tabular}{cccc}
\hline Test & $\mathbf{Q}_{\text {in }}(\mathbf{L} / \mathbf{s})$ & $\mathbf{Q}_{\text {fin }}(\mathbf{L} / \mathbf{s})$ & $\mathbf{S T}(\mathbf{s})$ \\
\hline $\mathrm{a}$ & 1.4 & 0.9 & $63-149$ \\
$\mathrm{~b}$ & 1.3 & 0.8 & $41-81$ \\
$\mathrm{c}$ & 1.2 & 0.7 & $38-46$ \\
\hline
\end{tabular}

In fact, although the rapid closing of the valve at section B is carried out manually and this may lead to slight differences in the manoeuvre times and, therefore, in the response of the system itself from one repetition to another also given the same test configuration (or $\mathrm{Q}_{\text {fin }}$ ), in general it is worth noting that, with reference to test (a) (see Figure 5a), the STs are around two minutes for repetitions 1, 2 and 5 , and around $60 \mathrm{~s}$ for repetitions 3 and 4 . For test (b) (see Figure 5b), the STs generally take on lower values than in test (a): in repetition 5, ST is equal to $40 \mathrm{~s}$ and in repetitions 1, 2, 3 and 4 the STs are about 80 s. Finally, ST continues to decrease, with values between 38 and 46 s for test (c) (see Figure 5c).

A further reduction of the initial flow rate within the system (tests (d), (e), (f) and (g) in Figure 5) leads to an anomalous behaviour of the PA-PRV, which tends in some cases to quickly stabilise around the set-point (see for example repetitions 1 and 2, in blue and red, respectively, in Figure 5f) but in others to reach the set-point in extremely prolonged times, longer than the sampling time of 6 min (see for example repetition 3, in yellow, in Figure 5f), or to stabilise around smaller values that are approximately 0.4 bar lower than the setting value (see for example repetitions 4 and 5 , in purple and green, respectively, in Figure 5f).

Thus, it is worth noting that even though the flow rate and the pressure in the system are related and clearly depend on several factors, including the pipeline parameters and the PRV characteristics and setting, PA-PRV behaviour, in terms of imposed downstream pressure, is correct and univocal for all the repetitions of the three test configurations characterized by a final flow rate higher than or equal to $0.7 \mathrm{~L} / \mathrm{s}$, whereas looking at the repetitions of each of the six test configurations characterized by a final flow rate between 0.7 and $0.2 \mathrm{~L} / \mathrm{s}$, it is evident that the downstream pressure is not uniquely defined in the face of the same flow rate.

This abnormal behaviour was also pointed out by Changklom and Stoianov [46], but for a diaphragm PRV, and it is defined as a deviation from the set-point or profile. The authors suggest as possible causes the blocking of control systems, the malfunction or failure of a physical component of the valve, insufficient inlet pressure, incorrect setting of the piston speed adjustment or the presence of trapped air in the control chamber. In the present case, however, the aforementioned causes should be ruled out. Indeed, the PA-PRV analysed in this study does not have an adjustment speed control system, as the operation of the device is based on the "Linear Flow Linear Control (LFLC)" technology, as described above, while any air trapped in the control chamber is eliminated by means of the air-relief valve placed on the valve body.

On the other hand, the tendency to stabilise around two set-points can be interpreted in light of a study presented by Dempster and Alshaikh [49]. In fact, after studying the behaviour of safety valves in an industrial environment subjected to determined flow conditions, the authors show that the behaviour of these devices could be influenced by the interaction between the force acting on the disc and the spring force, for which two different conditions of equilibrium are identified.

Based on this analysis, at flow rates lower than $0.7 \mathrm{~L} / \mathrm{s}$ the behaviour of the PA-PRV could be influenced by the operation of the pilot valve which, like the safety valve analysed in the study by Dempster and Alshaikh [49], seems to have two distinct points of equilibrium that lead the PA-PRV to stabilise at different values of pressure (see Figure $5 \mathrm{~d}-\mathrm{g}$ ). 
The difficulty of the PA-PRV in guaranteeing the set-point downstream of the valve is accentuated in tests (h) and (i): major instability occurs when the final flow rate $\mathrm{Q}_{\text {fin }}$ is lower than or equal to 0.2 $\mathrm{L} / \mathrm{s}$. Indeed, the pressure signal observed downstream of the PA-PRV starts to oscillate around an average value (lower than the set-point) with an amplitude of 0.5 bar and a frequency of about $0.5 \mathrm{~Hz}$ in response to the variation of the flow rate $\Delta \mathrm{Q}$. These oscillations are characterised by a persistent trend without damping and are comparable to harmonic motion (Figure 5h,i). In this case, an estimation of ST is not possible. A similar result was found in the study by Ulanicki and Skworcow [45], who showed an oscillatory behaviour under low-flow regimes due, however, to problems of stability of the electronic control system of the PRV and, in particular, to the fact that the dynamic gain, defined as the ratio between the variation of the pressure downstream of the PRV and the variation of the valve opening, does not decrease linearly with the opening. In this case, the device was controlled by a mechanical pilot, so the instability that emerged was probably an intrinsic characteristic of the device. Changklom and Stoianov [46] have confirmed the possibility of hydraulic instability in the device in the form of pressure oscillations. In particular, the authors differentiate between high- and low-frequency instabilities due, respectively, to incorrect sizing of the PRV and the interaction between the PRV and other devices.

In the present case, pressure data sampled upstream of the PA-PRV during the tests (h) and (i) did not show significant amplitude oscillations. Thus, the PA-PRV tends to split the hydraulic system into two parts, respectively, upstream and downstream of the PRV itself, a result similar to the one presented by Meniconi et al. [41]. Moreover, the presence of an expansion vessel between the centrifugal pump and the supply pipe rule out that this behaviour may be caused by an interaction between the pumping system and the PA-PRV.

Summing up, the first phase of tests highlights that the behaviour of the PA-PRV differs as the flow rate characterising the specific test decreases. In particular, the following characteristic types of behaviour can be observed:

- $\quad$ B1: for $\mathrm{Q}_{\text {fin }} \geq 0.7 \mathrm{~L} / \mathrm{s}$, the PA-PRV functions correctly, maintaining the downstream pressure around the setting value and showing variable time intervals of stabilisation of the piston, or STs;

- B2: for $0.7<\mathrm{Q}_{\text {fin }}<0.2 \mathrm{~L} / \mathrm{s}$, the PA-PRV tends to fail to maintain the imposed set-point, setting the downstream pressure around values lower than the set-point or showing extremely long stabilisation time intervals in order to reach the setting value. This behaviour can be related to an intrinsic difficulty of the pilot valve in reaching a single equilibrium configuration; and

- $\quad$ B3: for $\mathrm{Q}_{\mathrm{fin}} \leq 0.2 \mathrm{~L} / \mathrm{s}$, a condition of persistent instability is observed.

These three distinct behaviours that characterise the analysed piston valve can be distinguished with reference to the STs of the PA-PRV as a function of the final flow rate $Q_{\text {fin }}$ (Figure 6).

The green dots indicate the test repetitions during which the PA-PRV reached the set-point. In particular, with reference to $\mathrm{Q}_{\text {fin }} \geq 0.7 \mathrm{~L} / \mathrm{s}$ (tests (a), (b) and (c)), the STs and their scattering tend to decrease as the value of the test end flow rate $Q_{\text {fin }}$ decreases.

Yellow dots (Figure 6) identify the repetitions of tests (d), (e), (f) and (g) which showed a stabilisation of the PA-PRV around a lower value than the set-point or STs greater than the duration of the test $(6 \mathrm{~min})$. The red dots indicate the occurrence of unstable behaviour (B3).

With reference to the second phase of tests, Figure 7a,b shows the flow rate signals observed at the inlet section of the real district and imposed on the laboratory hydraulic system and the corresponding pressures sampled downstream of the PA-PRV (section G, set-point 2.4 bar) for periods AA and $\mathrm{BB}$, respectively. 


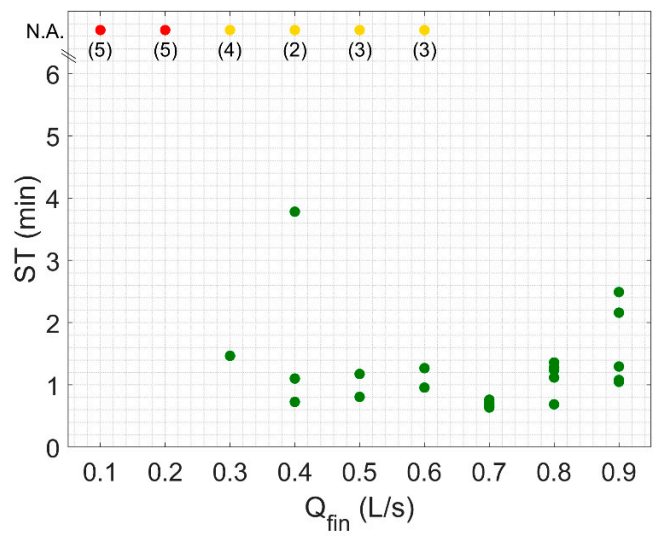

Figure 6. Stabilisation time intervals (or STs) in relation to the final flow rate $\mathrm{Q}_{\text {fin }}$ characterising the five repetitions of each test configuration. The green dots indicate repetitions of the tests in which the set-point was reached, the yellow dots indicate the repetitions in which the set-point was not reached; the unstable behaviour is highlighted with red dots. The number of repetitions of the tests in which the particular behaviour occurred is given in round brackets below the yellow and red dots.

(a)

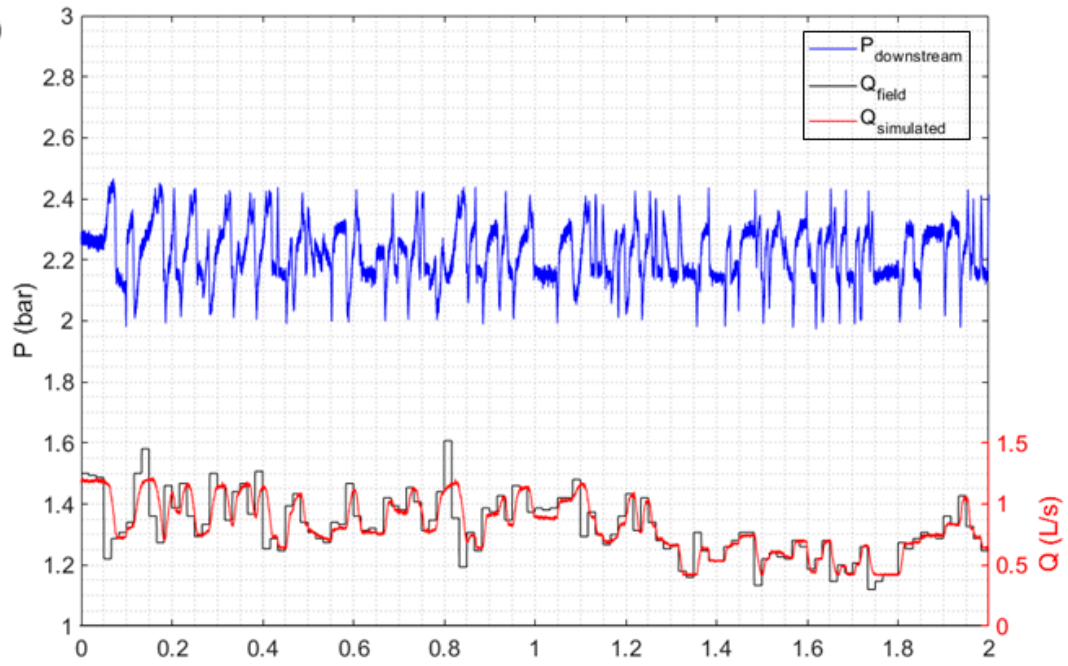

(b)

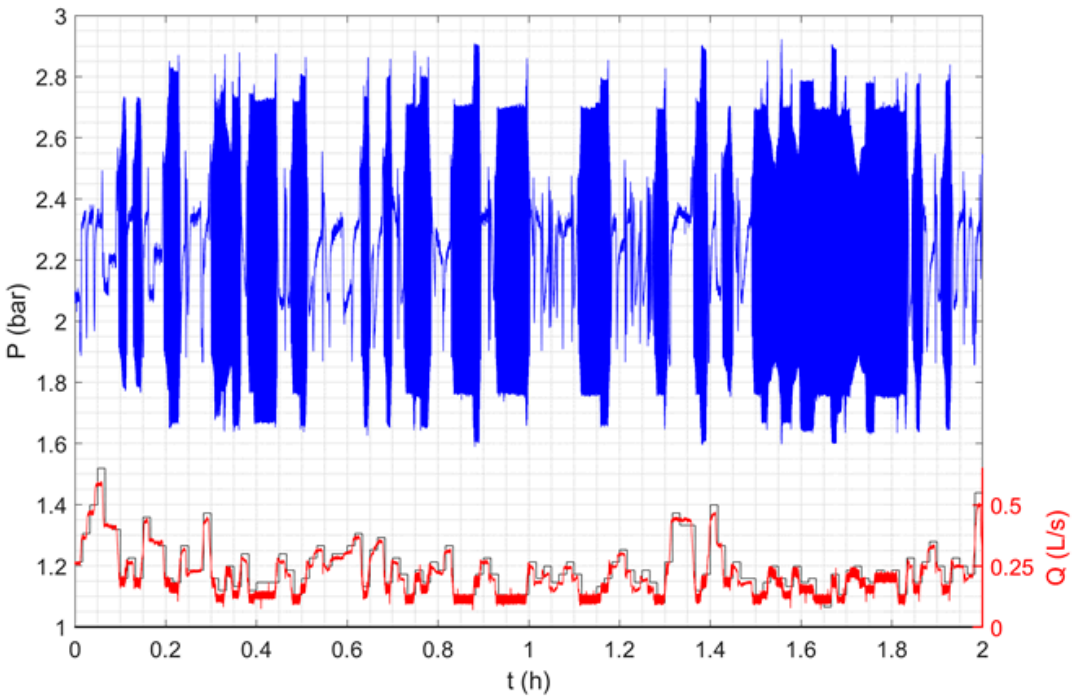

Figure 7. Pressure signal sampled downstream of the PA-PRV given the imposition of flow rates corresponding to periods (a) AA and (b) BB. The trends in the flow rates observed at the inlet section of the real district (in black) and simulated in the system (in red) are also shown. 
Firstly, it is worth noting that the imposition on the system of flow rates observed during period AA produces a simulated flow rate which tends, in general, to trace the observed one correctly. Some discrepancies are related to the manoeuvring speed and the adaptation time of the solenoid valve with remotely controlled modular opening at manoeuvring section $\mathrm{A}$, which tends to reproduce smaller, more gradual variations rather than large, sudden changes in discharge. With reference to the pressure signals, the set-point is not properly maintained with the imposition of the series of observed flow rates in period AA (see Figure 7a).

Pressure fluctuations between 2 and 2.5 bar due to the rapid variability of the flow rate regime are evident. From an operational standpoint, given the stabilisation times of the PA-PRV, which are in the order of one or more minutes, the rapid variability of the flow rate regime (1 min step) means that the PRV is unable to reach the set-point before the flow rate in the system varies again.

Moreover, when the flow rate in the system decreases below $0.7 \mathrm{~L} / \mathrm{s}$, the PA-PRV exhibits behaviours that can be traced back to B2 as characterised in the first phase of the tests.

For example, with reference to the time interval preceding the instant $t=1.8 \mathrm{~h}$ in Figure $7 \mathrm{a}$, the PA-PRV stabilises the downstream pressure around a value equal to $2.2 \mathrm{bar}$, lower than the set-point imposed despite the fact that the flow rate remains the same for approximately three minutes of simulation.

With the imposition of the series of flow rates observed in period BB (see Figure $7 \mathrm{~b}$ ), the pressure signals show that the set-point is not maintained and an instability occurs whenever the flow rate becomes smaller than or equal to $0.2 \mathrm{~L} / \mathrm{s}$. This behaviour can be related to the flow rate regime characterising the system, which oscillates between a maximum value of $0.7 \mathrm{~L} / \mathrm{s}$ and a minimum value of $0.1 \mathrm{~L} / \mathrm{s}$. This flow range causes the PRV to work between behaviours B2 and B3 previously defined: the instability of the PA-PRV at such low flow rates determines a pressure oscillation downstream of the device itself, which in this case is between 1.7 and 2.9 bar.

This second simulation is useful for highlighting how the occurrence of instability can occur under the ordinary operational conditions in a DMA and consequently subject a real system to stresses that are potentially harmful to pipes and hydraulic devices.

\section{Conclusions}

This study investigates the behaviours of a piston-actuated PRV (or, PA-PRV) installed in a hydraulic system and subjected to low flow conditions by means of laboratory tests. After the first phase of tests, three characteristic behaviours can be distinguished, corresponding to precise ranges of flow rate. The PA-PRV functions correctly at flow rates higher than or equal to $0.7 \mathrm{~L} / \mathrm{s}$, maintaining the downstream pressure around the setting value. At flow rates between 0.7 and $0.2 \mathrm{~L} / \mathrm{s}$, the PA-PRV tends to fail to maintain the imposed set-point, resulting in downstream pressures around values lower than the set-point or extremely long stabilisation time intervals before the setting value is reached. This behaviour can be related to an intrinsic difficulty of the pilot valve in finding a single equilibrium configuration. Finally, a condition of persistent instability is observed for flow rates lower than or equal to $0.2 \mathrm{~L} / \mathrm{s}$. The results of the second phase of analysis, in which the system was subjected to a series of flow rates observed at the inlet section of a real district metered area, confirm that the abnormal behaviour defined in the previous phase may potentially appear under the ordinary operational conditions of a water distribution network. In fact, under certain flow conditions in the system, the device tends not to maintain the set pressure and shows major instability when the flow falls below certain values. It is evident that the occurrence of these particular behaviours in the field implies potential technical and economic consequences in terms of damage to pipes and devices in the network. In order to confirm the obtained experimental results, future development will focus on static and dynamic characterization of the valve through a modelling approach.

Author Contributions: Conceptualization, V.M., R.Z. and S.A.; investigation, V.M. and R.Z.; writing-review and editing, V.M., S.A. and M.F. All authors have read and agreed to the published version of the manuscript. 
Conflicts of Interest: The authors declare no conflict of interest.

\section{References}

1. Alvisi, S. A New Procedure for Optimal Design of District Metered Areas Based on the Multilevel Balancing and Refinement Algorithm. Water. Resour. Manag. 2015, 29, 4397-4409. [CrossRef]

2. Chondronasios, A.; Gonelas, K.; Kanakoudis, V.; Patelis, M.; Korkana, P. Optimizing DMAs' formation in a water pipe network: The water aging and the operating pressure factors. J. Hydroinform. 2017, 19, 890-899. [CrossRef]

3. Ferrari, G.; Savic, D. Economic Performance of DMAs in Water Distribution Systems. Procedia Eng. 2015, 119, 189-195. [CrossRef]

4. Gomes, R.; Sousa, J.; Muranho, J.; Marques, A.S. Different Design Criteria for District Metered Areas in Water Distribution Networks. Procedia Eng. 2015, 119, 1221-1230. [CrossRef]

5. Gonelas, K.; Chondronasios, A.; Kanakoudis, V.; Patelis, M.; Korkana, P. Forming DMAs in a water distribution network considering the operating pressure and the chlorine residual concentration as the design parameters. J. Hydroinform. 2017, 19, 900-910. [CrossRef]

6. Grayman, W.M.; Murray, R.; Savic, D.A. Effects of Redesign of Water Systems for Security and Water Quality Factors. In Proceedings of the World Environmental and Water Resources Congress 2009, Kansas City, MO, USA, 17-21 May 2009; pp. 1-11.

7. Korkana, P.; Kanakoudis, V.; Patelis, M.; Gonelas, K. Forming District Metered Areas in a Water Distribution Network Using Genetic Algorithms. Procedia Eng. 2016, 162, 511-520. [CrossRef]

8. Okeya, I.; Hutton, C.; Kapelan, Z. Locating Pipe Bursts in a District Metered Area Via Online Hydraulic Modelling. Procedia Eng. 2015, 119, 101-110. [CrossRef]

9. Awad, H.; Kapelan, Z.; Savić, D. Analysis of Pressure Management Economics in Water Distribution Systems. In Proceedings of the Water Distribution Systems Analysis Conference 2008, Kruger National Park, South Africa, 17-20 August 2008.

10. Parra, S.; Krause, S. Pressure management by combining pressure reducing valves and pumps as turbines for water loss reduction and energy recovery. Int. J. Sustain. Dev. Plan. 2017, 12, 89-97. [CrossRef]

11. Signoreti, R.O.S.; Camargo, R.Z.; Canno, L.M.; Pires, M.S.G.; Ribeiro, L.C.L.J. Importance of pressure reducing valves (PRVs) in water supply networks. JPCS 2016, 738, 012026. [CrossRef]

12. Thornton, J.; Lambert, A.O. Pressure management extends infrastructure life and reduces unnecessary energy costs. In Proceedings of the IWA Special Conference Water Loss 2007, Bucharest, Romania, 23-26 September 2007; pp. 5115-5121.

13. Araujo, L.S.; Ramos, H.M.; Coelho, S.T. Pressure Control for Leakage Minimisation in Water Distribution Systems Management. Water Resour. Manag. 2006, 20, 133-149. [CrossRef]

14. Campisano, A.; Modica, C.; Reitano, S.; Ugarelli, R.; Bagherian, S. Field-Oriented Methodology for Real-Time Pressure Control to Reduce Leakage in Water Distribution Networks. J. Water Res. Plan. Manag. 2016, 142, 04016057. [CrossRef]

15. Eliades, D.G.; Polycarpou, M.M. Leakage fault detection in district metered areas of water distribution systems. J. Hydroinform. 2012, 14, 992-1005. [CrossRef]

16. Fontana, N.; Giugni, M.; Glielmo, L.; Marini, G.; Zollo, R. Real-Time Control of Pressure for Leakage Reduction in Water Distribution Network: Field Experiments. J. Water Res. Plan. Manag. 2018, 144, 04017096. [CrossRef]

17. Samir, N.; Kansoh, R.; Elbarki, W.; Fleifle, A. Pressure control for minimizing leakage in water distribution systems. Alex. Eng. J. 2017, 56, 601-612. [CrossRef]

18. AbdelMeguid, H.; Skworcow, P.; Ulanicki, B. Mathematical modelling of a hydraulic controller for PRV flow modulation. J. Hydroinform. 2011, 13, 374-389. [CrossRef]

19. Janus, T.; Ulanicki, B. Hydraulic Modelling for Pressure Reducing Valve Controller Design Addressing Disturbance Rejection and Stability Properties. Procedia Eng. 2017, 186, 635-642. [CrossRef]

20. Janus, T.; Ulanicki, B. Improving Stability of Electronically Controlled Pressure-Reducing Valves through Gain Compensation. J. Hydraul. Eng. 2018, 144, 04018053. [CrossRef]

21. Khezzar, L.; Harous, S.; Benayoune, M. Modeling of Pressure Reducing Valves Revisited. In Proceedings of the 29th Annual Water Resources Planning and Management Conference, Tempe, AZ, USA, 6-9 June 1999. 
22. Page, P.R.; Abu-Mahfouz, A.M.; Yoyo, S. Parameter-Less Remote Real-Time Control for the Adjustment of Pressure in Water Distribution Systems. J. Water Resour. Plan. Manag. 2017, 143, 04017050. [CrossRef]

23. Prescott, S.L.; Ulanicki, B. Dynamic Modeling of Pressure Reducing Valves. J. Hydraul. Eng. 2003, 129, 804-812. [CrossRef]

24. Prescott, S.L.; Ulanicki, B. Improved Control of Pressure Reducing Valves in Water Distribution Networks. J. Hydraul. Eng. 2008, 134, 56-65. [CrossRef]

25. Freni, G.; De Marchis, M.; Napoli, E. Implementation of pressure reduction valves in a dynamic water distribution numerical model to control the inequality in water supply. J. Hydroinform. 2014, 16, $207-217$. [CrossRef]

26. Covelli, C.; Cozzolino, L.; Cimorelli, L.; Della Morte, R.; Pianese, D. Optimal Location and Setting of PRVs in WDS for Leakage Minimization. Water Resour. Manag. 2016, 30, 1803-1817. [CrossRef]

27. Creaco, E.; Pezzinga, G. Comparison of Algorithms for the Optimal Location of Control Valves for Leakage Reduction in WDNs. Water 2018, 10, 466. [CrossRef]

28. Dai, P.D.; Li, P. Optimal Pressure Regulation in Water Distribution Systems Based on an Extended Model for Pressure Reducing Valves. Water Resour. Manag. 2016, 30, 1239-1254. [CrossRef]

29. Giugni, M.; Fontana, N.; Ranucci, A. Optimal Location of PRVs and Turbines in Water Distribution Systems. J. Water. Res. Plan. Manag. 2014, 140, 06014004. [CrossRef]

30. Gupta, R.; Baby, A.; Arya, P.V.; Ormsbee, L. Upgrading Reliability of Water Distribution Networks Recognizing Valve Locations. Procedia Eng. 2014, 89, 370-377. [CrossRef]

31. Liberatore, S.; Sechi, G.M. Location and Calibration of Valves in Water Distribution Networks Using a Scatter-Search Meta-Heuristic Approach. Water Resour. Manag. 2009, 23, 1479-1495. [CrossRef]

32. Di Nardo, A.; Cavallo, A.; Di Natale, M.; Greco, R.; Santonastaso, G.F. Dynamic Control of Water Distribution System Based on Network Partitioning. Procedia Eng. 2016, 154, 1275-1282. [CrossRef]

33. De Paola, F.; Giugni, M.; Portolano, D. Pressure Management through Optimal Location and Setting of Valves in Water Distribution Networks Using a Music-Inspired Approach. Water Resour. Manag. 2017, 31, 1517-1533. [CrossRef]

34. Pecci, F.; Abraham, E.; Stoianov, I. Global optimality bounds for the placement of control valves in water supply networks. Optim. Eng. 2019, 20, 457-495. [CrossRef]

35. Saldarriaga, J.; Salcedo, C.A. Determination of Optimal Location and Settings of Pressure Reducing Valves in Water Distribution Networks for Minimizing Water Losses. Procedia Eng. 2015, 119, 973-983. [CrossRef]

36. Tricarico, C.; Morley, M.S.; Gargano, R.; Kapelan, Z.; de Marinis, G.; Savić, D.; Granata, F. Integrated Optimal Cost and Pressure Management for Water Distribution Systems. Procedia Eng. 2014, 70, 1659-1668. [CrossRef]

37. Wright, R.; Abraham, E.; Parpas, P.; Stoianov, I. Optimized Control of Pressure Reducing Valves in Water Distribution Networks with Dynamic Topology. Procedia Eng. 2015, 119, 1003-1011. [CrossRef]

38. Campisano, A.; Creaco, E.; Modica, C. RTC of Valves for Leakage Reduction in Water Supply Networks. J. Water Res. Plan. Manag. 2010, 136, 138-141. [CrossRef]

39. Klarecki, K.; Rabsztyn, D. Static and dynamic properties of selected hydraulic pressure reducing. IOP Conf. Ser. Mater. Sci. Eng. 2018, 400, 022035. [CrossRef]

40. Mao, X.; Hu, J.; Wu, C.; Liu, Y.; Liu, Y. Characteristics analysis of a water hydraulic pilot-operated pressure-reducing valve. IOP Conf. Ser. Earth Environ. Sci. 2017, 69, 012072. [CrossRef]

41. Meniconi, S.; Brunone, B.; Ferrante, M.; Mazzetti, E.; Laucelli, D.B.; Borta, G. Transient Effects of Self-adjustment of Pressure Reducing Valves. Procedia Eng. 2015, 119, 1030-1038. [CrossRef]

42. Meniconi, S.; Brunone, B.; Mazzetti, E.; Laucelli, D.B.; Borta, G. Pressure Reducing Valve Characterization for Pipe System Management. Procedia Eng. 2016, 162, 455-462. [CrossRef]

43. Meniconi, S.; Brunone, B.; Mazzetti, E.; Laucelli, D.B.; Borta, G. Hydraulic characterization and transient response of pressure reducing valves: Laboratory experiments. J. Hydroinform. 2017, 19, 798-810. [CrossRef]

44. Moussou, P.; Gibert, R.J.; Brasseur, G.; Teygeman, C.; Ferrari, J.; Rit, J.F. Instability of Pressure Relief Valves in Water Pipes. J. Press. Vessel Technol. 2010, 132, 041308. [CrossRef]

45. Ulanicki, B.; Skworcow, P. Why PRVs Tends to Oscillate at Low Flows. Procedia Eng. 2014, 89, $378-385$. [CrossRef]

46. Changklom, J.; Stoianov, I. Fault Detection and Diagnosis for Pressure Control Valves in Water Supply Networks. In Proceedings of the Computing and Control for the Water Industry Conference 2017, Sheffield, UK, 5-7 September 2017; p. F143. 
47. Saisanket (2019). Available online: https://www.saisanketvalves.com (accessed on 15 November 2019).

48. Alvisi, S.; Luciani, C.; Franchini, M. Using water consumption smart metering for water loss assessment in a DMA: A case study. Urban Water J. 2019, 16, 77-83. [CrossRef]

49. Dempster, W.; Alshaikh, M. An Investigation of the Two Phase Flow and Force Characteristics of a Safety Valve. Procedia Eng. 2015, 130, 77-86. [CrossRef] 